\title{
Demographic and economic determinants of migration
}

\section{Push and pull factors drive the decision to stay or move}

Keywords: migration, determinants, costs, networks

\section{ELEVATOR PITCH}

There are a myriad of economic and non-economic forces behind the decision to migrate. Migrants can be "pushed" out of their home countries due to deteriorating economic conditions or political unrest. Conversely, migrants are often "pulled" into destinations that offer high wages, good health care, and strong educational systems. In making their decision, individuals compare the net benefits of migration to the costs. By better understanding what forces affect specific migrant flows (e.g. demographic characteristics, migrant networks, and economic conditions), policymakers can set policy to target (or reduce) certain types of migrants.

\section{KEY FINDINGS}

\section{Pros}

(- Increases in income differentials across countries often lead to increases in migrant flows.

๑ Strong migrant networks have historically played a large role in enhancing migrant flows.

- Tax and government transfer policies (e.g. welfare, health care, and educational systems) can attract migrants.

๑ Migration serves as a form of insurance for households and the desire to remit earnings from abroad may form part of the household decision to migrate.

- Macroeconomic conditions at home and abroad can affect the flow of migrants.

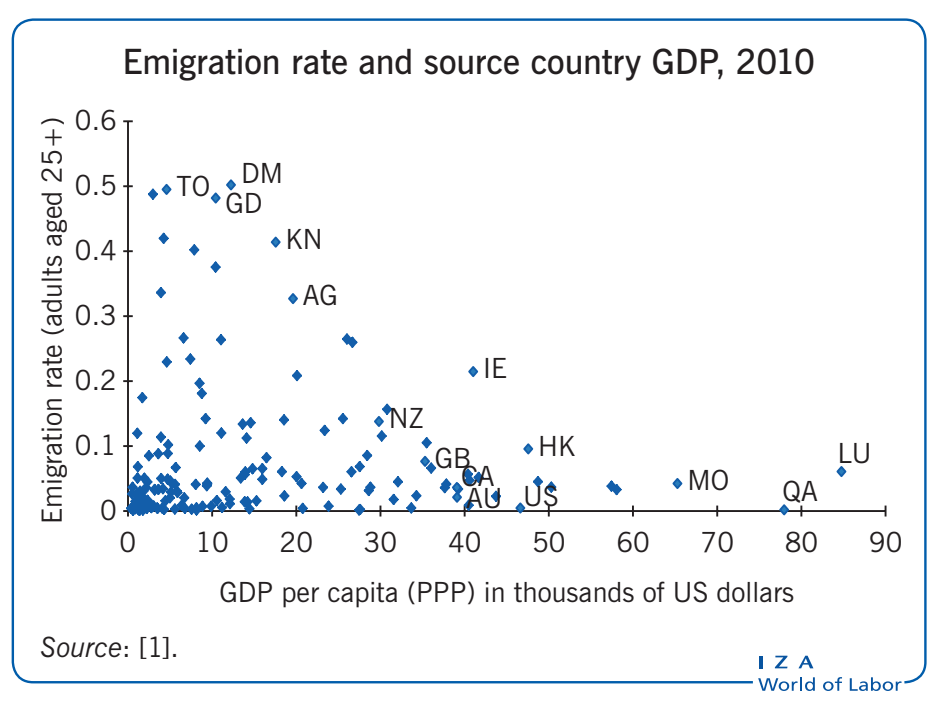

\section{Cons}

- Migration costs are central to the migration decision, they take many forms (e.g. transportation, job search, visa fees, smuggler fees) and often vary with distance.

- Strict migration policy acts as a constraint in the migration decision.

- Demographic factors such as age, education, marital status, and language impact one's willingness to migrate.

- Worsening political and environmental conditions abroad and/or improving conditions at home can lead to less migration.

\section{AUTHOR'S MAIN MESSAGE}

Many factors affect the net benefits and costs of migration and thus impact the decision to migrate. Studies indicate that the key determinants of migration include the availability of migrant networks, differences in income across countries, and demographic factors, but many other factors also affect the migration decision. Constraints created by tighter migration policy represent the most significant hurdle to migration. Prior to making significant changes in migration policy, policymakers should make sure they sort out which factors are driving each migrant flow so they are better prepared to welcome their new migrants. 


\section{MOTIVATION}

Consider the forces that would motivate people and their families to leave their home country and move to another to start a new life. Some of those forces are likely economic: a higher standard of living, the chance to find a better job, or a more comfortable safety net. However, other forces are at play as well, such as superior amenities (e.g. air quality), a democratic political system, and access to a better education system. Between 2000 and 2010, the growth in the migrant stock worldwide increased by 4.6 million each year [2]. Many more would like to migrate if given the opportunity. Understanding the key determinants of migration patterns is hence essential when considering the implications of immigration policy. Setting immigration policy without thinking through the various mechanisms that are driving migrant flows is misguided and could lead to unintended consequences.

It should be noted that this article focuses on international migration, not internal migration. However, many of the determinants discussed in this article would apply to internal migration as well.

\section{Framework for making migration decisions}

It is important to develop a framework in thinking through the various determinants of migration. A simple "Roy model" examines how self-selection into migration affects the distribution of income. Inherent to the Roy model is a net present value (NPV) calculation for migration that allows one to emphasize the forward-looking nature of the decision to migrate. In fact, individuals (or households) will decide to migrate only if the NPV is positive, that is, if the (discounted) net benefits to migration outweigh the (discounted) costs. Importantly, when calculating NPV, the benefits and costs of migration in future periods must be adjusted (through the use of a fixed discount rate) as a way to accurately compare values over time. The NPV model of migration is implicitly rooted in utility or income maximization-it assumes that people base their decision to migrate on whether migration makes them better off over a long period of time.

\section{DISCUSSION OF PROS AND CONS}

\section{Factors enhancing migration}

\section{Income differentials and income inequality}

The net benefits to migration include the increase in income (or "utility") gained by migrating, or the difference between origin country (where migrants are moving from) and host country (where migrants are moving to) income. Historically, worldwide migration patterns typically flow from south to north, where the south is often considered poorer while the north is richer (this is a generalization but applies in many historical migrant patterns). Workers in poorer countries are looking for higher wages and better employment opportunities, which can usually be found in richer countries. As a result, nearly every economic model of migration incorporates income differentials and finds them to be an important factor when trying to explain migrant flows in a given period. Income can serve as a "push" factor: low income levels can push migrants out of their 


\section{Push and pull factors of migration}

Push factors are conditions that propel people to leave the origin country, while pull factors are conditions that entice people to enter a destination country.

Figure 1. Push and pull factors of migration

\section{Push factors}

Economic

Poverty/low wages

High taxes

High unemployment

Overpopulation

Non-economic

Discrimination

Poor health care

War or oppression

Corruption

Crime

Compulsory military service

Natural disaster

Famine

\section{Pull factors}

\section{Economic}

Demand for labor

High wages

Generous welfare benefits

Good healthcare and education systems

Strong economic growth

Technology

Low cost of living

Non-economic

Family and friends/networks

Rights and freedoms

Property rights

Law and order

Amenities

Source: Bansak, C., N. Simpson, and M. Zavodny. The Economics of Immigration. Oxford: Routledge, 2015 [1].

home country, as shown in the illustration on page 1. Conversely, high income levels can serve to "pull" migrants into a specific country or region (Figure 1).

In many cases of south-to-north migration, both push and pull forces are at play. Over time, income differentials between countries may change, which can affect migrant flows; as income differentials increase (either by origin country income decreasing and/or host country income increasing), there is a larger incentive to migrate. The reverse holds true when income differentials decrease. In this case, the net gain to migration falls, so fewer workers find it attractive to migrate abroad. As such, income levels and differences in income, by affecting the net benefits of migration, are typically considered among the most important determinants in the decision to migrate.

Income variability can also affect the migration decision. If income is highly volatile, workers may be incentivized to search for more stable income streams, especially in countries where credit markets are nonexistent or incomplete. (Economic theory indicates that individuals can save or borrow to smooth out their income streams, but in some countries access to credit markets is limited.) Thus, less income volatility in the host country may increase the net benefits of migration and/or decrease migration costs. In addition, countries with high amounts of income inequality often have large gaps between wages for high-skilled workers and low-skilled workers. Similar to income levels, the distribution of income can work as a push or pull factor. "There is a higher incentive 
to migrate if one is poor among rich than if one is poor among poor," suggesting that income inequality is a push factor [3]. At the same time, income inequality may act as a pull factor: potential migrants with high levels of education may be pulled to countries where the return to skills is high.

\section{Networks: Family and friends}

Nearly every contemporary study of the determinants of migration considers the importance of migrant networks in the host country. The most typical way to measure networks is to control for the stock of migrants from a given migrant's origin country in the host country (or region). Since migrant stocks are captured in most national censuses, network effects have been fairly straightforward to measure. Research consistently finds a strong, positive effect of migrant networks on predicting new migrant flows. That is, migrants are often attracted to host countries with large populations of migrants (diasporas) from the same country of origin. Having a community of people who speak the same language and share the same culture leads to lower psychological costs associated with migration. Networks may also reduce the economic costs of migration by helping migrants find employment and housing, as well as helping the migrant assimilate to their new location. Over time, as migrants assimilate to their new country, their reliance on the migrant community may decrease as they learn the host country's culture and language, thereby reducing the net benefits created by the local migrant community.

Estimates suggest that if the stock of migrants from a specific country increases by 1,000 people, then the flow of migrants will increase by 4.7 people per year, although the effect dampens as the migrant stock gets bigger, suggesting that migrant networks have the largest effect when migrant stocks are small [4]. In the majority of studies decomposing the various determinants of migration, migrant networks are usually the most important predictor of migrant flows. For example, migrant stocks explain more than $70 \%$ of the observed variation in migrant flows to OECD countries [5]. In addition, migrant networks tend to matter most for migrants coming from poor origin countries [6].

\section{Taxes, transfers, and the government safety net}

Taxes and government transfers (e.g. unemployment insurance, welfare) often serve as pull factors rather than push factors (but in theory they could be both). Income taxes, for example, reduce the return to working and hence lower the net benefits of migration. Countries with progressive income taxes (where higher incomes are taxed more heavily) may deter the flow of high-skilled migrants since lower after-tax wages will reduce the incentive to migrate. However, low-skilled migrants will be taxed very little (if at all) in a country with progressive taxes, so they may have larger incentives to migrate. In a recent study, migrant flows are found to be lower to countries with higher tax burdens [7]. Other types of taxes will similarly distort the migration decision. For example, countries with high consumption (or sales) taxes have higher costs of living (especially for low-income migrants), which increases migration costs. Similarly, capital gains taxes may discourage migrants who seek investment opportunities abroad.

The availability of social insurance programs appears to affect whether or not people migrate. Receiving access to strong health care and educational systems in the host country may increase the benefit of migration and serve as a strong pull factor. In fact, 
families often migrate abroad primarily for educational reasons; they want their children to have better educational opportunities than what are offered back home.

Countries with generous government transfers may attract migrants; these locales are often considered "welfare magnets." The welfare magnet hypothesis suggests that migrants choose their destination based on the generosity of public assistance programs. Welfare payments, for example, can be viewed as a substitute for earnings during the time spent searching for a job. Government transfers may thus attract certain types of migrants that would be eligible for these types of benefits. Increasingly, governments are making it more difficult for migrants to receive government transfers (at least in the period immediately following migration). That is, migrants often have to work in the host country for a few years before becoming eligible for government benefits. Most of the empirical evidence on the subject finds that countries with more generous public assistance benefits, as measured by social expenditures as a percentage of GDP, do not necessarily attract more migrants [6]. However, migrants from the poorest countries of origin appear to be more likely to migrate to countries with relatively generous programs.

\section{Insurance and remittances}

For many, the decision to migrate is a household-level decision. The family unit as a whole must decide whether the entire family will migrate or if it will send only one member of the household abroad. In this way, migration may be a form of insurance against uncertainty in the form of household- and macro-level shocks. Remittances are the primary insurance mechanism for migrants; they allow family members who migrate abroad to send a portion of their income back home. In addition, families often help to relax the tight borrowing constraints that potential migrants face, especially in helping to finance the move. Households may be motivated by the insurance that migration provides, either by smoothing out macroeconomic cycles over time or through cash or in-kind transfers received from family members abroad. Overall, using migration as a form of household-level insurance against individual or aggregate shocks can help reduce volatility in household incomes and increase the net benefit to migration over time. For some families (especially in relatively poor countries of origin), remittances can represent a significant fraction of household income, compounding these effects.

\section{Macroeconomics factors: Exchange rates, business cycles, unemployment}

Besides income (as measured by per capita GDP), many other macroeconomic factors impact the migration decision. Accordingly, exchange rates directly affect relative prices abroad and, hence, purchasing power. A strong foreign currency (relative to the currency in the country of origin) will allow the money earned abroad to buy more back home, increasing the net benefit to migration. Conversely, a strong home currency will reduce the value of earnings abroad. Exchange rates operate through both wages and remittances in affecting the migration decision.

As mentioned above, income volatility driven by business cycles (e.g. macroeconomic fluctuations) or changes in employment status can push migrants out of countries of origin or pull them into host countries. High unemployment in a country of origin may act as a push factor. In addition, migrants typically move to regions with low unemployment [8]. Conversely, in times of economic recession, high unemployment rates in the host country deter migration, as evident in the 2007-2009 global financial crisis. 


\section{Well-being, ability, optimism, aspirations, risk tolerance}

Many other non-economic factors may influence the decision to migrate as well. Recent work using measures of well-being (or happiness) have found a link between aggregate well-being and migrant flows. For example, fewer people move out of relatively unhappy countries as aggregate happiness levels increase in those countries [9]. Optimism may also affect the migration decision: the net benefit of migration may seem larger for an optimistic person than for a pessimistic person. Researchers have found some evidence indicating that migrants tend to be more optimistic than non-migrants.

Moreover, people's innate ability, ambitions, or risk aversion likely form part of the migration decision. One could argue that ambitious people are more likely to migrate, while people who are risk averse may not be willing to gamble by migrating to a new country (the costs of migration may seem insurmountable to them). However, many of these traits are unobservable in the data as they can be difficult to quantify.

\section{Hurdles to migration}

There are several factors that make migration more difficult; some of these factors reduce the net benefits of migration, while most directly increase the costs, thereby reducing the NPV of migration and the incentives to migrate.

\section{Migration costs}

Obviously, the direct economic costs of migration include the travel costs associated with the move. These generally depend on the distance traveled as airfare and other travelrelated costs typically increase with distance. The gravity model of migration explicitly considers the role of distance in estimating migrant flows. In nearly every study where the gravity model is employed, distance is significantly and negatively correlated with migrant flows. In addition, people often have to pay significant fees for visas and resident permits to gain legal entry. Visa fees and costs for permits vary significantly across both origin and host countries.

In addition, migration is an uncertain endeavor, so people seek information about the potential host country. These information costs (e.g. time) can be high but are constantly decreasing due to technological progress. A potential migrant can now acquire better information about the availability of housing, jobs, and government benefits, for example, in advance of making the decision to migrate. Technological improvements thereby lower migration costs, which, in turn, increase migrant flows.

\section{Immigration policy}

Immigration policy plays a significant role in limiting the flow of international migrants. Some countries make it difficult for people to leave; however, more common is to restrict the number of people entering a country each year. When estimating the determinants of migration, it is important to control for host country immigration policy. Immigration policy can vary over time, so actual and/or expected changes in immigration policy impact the NPV of migration and alter the flow of migrants. The extent to which a country protects its borders and imposes its immigration policy is important; countries which are known to be relatively easy to enter may be more attractive to potential migrants. In contrast, when 
countries enforce their immigration policy (such as after a major recession), the costs of migrating may become sufficiently high to discourage migration. Currently, for example, the US continues to put an emphasis on border enforcement and deportation, making it more difficult to migrate to the US. As a result, those attempting to cross the border without a visa have seen the costs associated with paying a smuggler increase and may be forced to choose a more hazardous crossing point.

In most theoretical models of migration, immigration policy serves as a proxy for migration costs. Countries with relaxed immigration policy will be less costly to move to, while countries with tight policy (i.e. well-enforced) will be more costly. Consider the extreme case in which no people are allowed to migrate-the costs of migration always exceed the benefits. For all other cases, a positive flow of migrants suggests that the net benefits of migration exceed the costs for some migrants.

\section{Demographic characteristics}

The characteristics of potential migrants have long been a central part of explaining who migrates and who does not. It is important to note that those who migrate for work purposes can be quite different than those who migrate for family reunification. Moreover, each migrant flow is unique in terms of the demographic characteristics, including age, gender, marital status, educational attainment, and so on. Labor migrants are often young, since they will have more time to realize the expected benefits of migration. Historically, labor migrants were typically working-age men, but, increasingly, migrant flows consist of women and families in search of employment abroad (and in some cases joining families already in the host country). Marital status is also important, with married people typically being less likely to migrate on their own and more likely to return home sooner.

The reasons driving the migration decision may be very different depending on the skill or education level of the migrant. In fact, there are important differences in the response of recent migrant flows on the basis of gender, country of origin, and skill level. For example, short-term income fluctuations pull less-educated male immigrants into the US, whereas long-term income trends push less-educated male immigrants out of their countries of origin [10]. In addition, studies typically find that migrants are healthier than nonmigrants in the origin country and natives in the host country [11], and migration rates are higher among people who speak the same language as the host country. Speaking the same language and being healthier may lower migration costs since the transitions into the culture and work are easier.

Overall, nearly every study of migration finds a significant role for demographic characteristics in explaining migrant populations. The set of characteristics that matters most varies significantly over time and across specific migrant flows. For example, the role of language differences may matter less in the future as English increasingly becomes the lingua franca of the world.

\section{Political and environmental conditions}

When countries are different from one another in terms of regulations and political situations, the costs of migrating between those countries could be quite high and may reduce the NPV of migration. Moreover, worsening political conditions abroad and/or 
improving conditions at home can reduce the incentive to migrate. Significant differences in the political conditions between countries may partially explain why people do not migrate between them.

Environmental factors such as worsening air quality in the host country can discourage migration. Conversely, improvements in the quality of life in the country of origin may also reduce the incentive to migrate.

\section{Other considerations}

While political and environmental factors can act as hurdles to migration, they can also serve as push and pull factors. Complicated political circumstances that create uncertainty in the origin country can serve as a push factor, while countries that are well-functioning democratic societies may attract new migrants, thereby increasing the benefits of migration. Push factors related to a country's political situation include war, oppression, corruption, crime, or discrimination, while pull factors consist of established property rights, law and order, and freedom. Measures of political freedom produced by the Heritage Foundation, for example, are often included in empirical analyses and are found to be important predictors of migrant flows [12].

War has been among the leading causes of large migrant flows historically. Repressive political regimes often drive people to leave their home country for fear of persecution, increasing the NPV of migration. Corruption often increases the cost of doing business, so many people who do not want to participate in bribery are pushed out of their (corrupt) origin country and pulled into a country with well-established property rights and rule of law. In addition, civil wars, upheavals, and human rights violations are well-documented push factors [13].

Environmental conditions may push migrants out of their country of origin, especially in the short term. Natural disasters can lead to a dramatic uptick in migration as households experience a large sudden (and often uninsurable) shock. Famines, much like natural disasters, can also push people out of their home country.

Push and pull factors affect the NPV calculation for all migrants, whether they are legal or illegal, low-skilled or high-skilled, young or old. It is important to note that some factors play bigger roles for certain migrant groups because of immigration policy. For example, if a country admits migrants based primarily on family preferences, the pull factor of family may matter a lot for legal migrants. Meanwhile, economic conditions may matter more for illegal migrants. In many countries, illegal migrants enter mainly to work, while legal migrants enter for a wider variety of reasons, including family ties. Regardless of their legal status, low-skilled and high-skilled workers alike are affected by the push and pull of relative economic conditions. However, high-skilled workers may have more resources to cover the costs associated with migration since they are likely to have higher household income.

In addition, the timing of migration is important. In thinking through the net benefits of migration, an individual or household may decide to move abroad and have plans to return home at a certain point in time once they have maximized the benefits of living abroad, especially if they left family behind in the country of origin. 


\section{LIMITATIONS AND GAPS}

As with most studies of migration, finding reliable cross-country data over time is nontrivial. Most countries keep track of people coming into their countries (immigrants), while very few countries accurately measure people moving out of their countries (emigrants). In addition, accurately measuring the flow of illegal migrants into a country is complicated (although not impossible).

In an ideal world, countries would keep track of people coming into and people leaving their countries over time. Importantly, detailed data on each migrant would be available to researchers, including a complete set of demographic information, their migration history, country of origin, reasons for migration, and migrant status (e.g. the type of visa they entered under). Increasingly, countries are doing a better job of collecting some of this information, though detailed demographic information is not always included. Ethnographic surveys provide many demographic details but are often not representative of migrant flows as a whole. In addition, given the political sensitivities around setting migration policies, countries are not often willing to share their comprehensive data sets with researchers. To complicate matters, relatively poor countries cannot invest in systems that can handle this level of data collection.

In order to better understand the various reasons behind complex migration decisions, governments will have to collect better data and then be willing to share them with researchers. The EU, for example, has been the most willing to both collect the relevant data and share them publicly, which has generated a sizable increase in the research done on EU migrant flows in recent years. Still, more countries, rich and poor alike, need to cooperate; perhaps international organizations can help to overcome the hurdles with better data collection. By having comprehensive data sets of worldwide migrant flows, researchers can better understand and disentangle the various determinants of migration.

\section{SUMMARY AND POLICY ADVICE}

Researchers have analyzed a variety of migrant flows using a multitude of empirical approaches to be able to tease out the key drivers of migration. Income differentials, migrant networks, and demographic factors are found to be robust predictors of migrant flows. Many other factors identified in this article have also been found to be correlated with migrant flows; however, their ability to predict flows is lower.

Policymakers must carefully consider the key set of determinants for the particular flow of migrants entering their country. It would be difficult to set effective policy without first understanding both the push and pull factors. For example, if the goal is to reduce the number of migrants entering a country in cases when network effects are most relevant, then policy should be changed to be less centered on family preferences. Conversely, if income differentials are driving flows, perhaps migrants could be more heavily taxed (via entry or visa fees) to reduce flows.

If there were a comprehensive database of worldwide migration flows, researchers could perform systematic statistical analyses to sort out which factors are driving each migrant flow. They could then quantify the extent to which certain factors matter. Having reliable estimates about how migrant flows respond to GDP fluctuations could be 
particularly helpful for governments who want to set policy to slow the outflow or inflow of migrants. Likewise, suppose policymakers had a better understanding of the extent to which households in a certain country use migration as an insurance mechanism to buffer against fluctuations in household income: Governments could work with nongovernmental organizations to develop affordable household insurance schemes as a way of reducing the incentive to migrate. Or suppose host countries had a better understanding of the demographic characteristics of their specific migrant populations so that services could be targeted specifically toward their needs to ensure better integration into the host country. Perhaps most importantly, if a government could quantify (with relative certainty) the change in migrant flows as a result of a change in migrant policy (i.e. increasing visa application fees or granting amnesty to undocumented migrants), governments could make well-informed policy decisions.

\section{Acknowledgments}

The author thanks an anonymous referee and the the IZA World of Labor editors for many helpful suggestions on earlier drafts. The author also thanks Cynthia Bansak and Chad Sparber. Previous work of the author contains a larger number of background references for the material presented here and has been used intensively in parts of this article [1], [9], [10].

\section{Competing interests}

The IZA World of Labor project is committed to the IZA Guiding Principles of Research Integrity. The author declares to have observed these principles.

(C) Nicole B. Simpson 


\section{REFERENCES}

\section{Further reading}

Borjas, G. J. Immigration Economics. Cambridge, MA: Harvard University Press, 2014.

Özden, Ç., and M. W. Schiff (eds). International Migration, Economic Development \& Policy. Washington, DC: World Bank Publications, 2007.

\section{Key references}

[1] Bansak, C., N. Simpson, and M. Zavodny. The Economics of Immigration. Oxford: Routledge, 2015.

[2] United Nations and OECD. World Migration in Figures. United Nations and OECD, 2013.

[3] Rotte, R., and M. Vogler. Determinants of International Migration: Empirical Evidence for Migration from Developing Countries to Germany. IZA Discussion Paper No. 12, 1998.

[4] Clark, X., T. J. Hatton, and J. G. Williamson. "Explaining US Immigration, 1971-1998." Review of Economics and Statistics 89 (2007): 359-373.

[5] Beine, M., F. Docquier, and C. Özden, "Diasporas." Journal of Development Economics 95 (2011): $30-41$.

[6] Pedersen, P. J., M. Pytlikova, and N. Smith. "Selection and network effects-Migration flows into OECD countries 1990-2000.” European Economic Review 52:7 (2008): 1160-1186.

[7] Geis, W., S. Uebelmesser, and M. Werding, "How do migrants choose their destination country? An analysis of institutional determinants." Review of International Economics 21 (2013): 825-840.

[8] Hunt, J. "Staunching emigration from East Germany: Age and the determinants of migration." Journal of the European Economic Association 4:5 (2006): 1014-1037.

[9] Polgreen, L., and N. Simpson. "Happiness and international migration." Journal of Happiness Studies 12:5 (2011): 819-840.

[10] Simpson, N., and C. Sparber. "The short- and long-run determinants of less-educated immigrant flows into US states." Southern Economic Journal 80:2 (2013): 414-438.

[11] Kennedy, S., M. P. Kidd, J. T. Mcdonald, and N. Biddle. "The healthy immigrant effect and immigrant selection: Evidence from four countries." Journal of International Migration and Integration 16:2 (2015): 317-332.

[12] Karemera, D., V. I. Oguledo, and B. Davis. "A gravity model analysis of international migration to North America." Applied Economics 32:13 (2000): 1745-1755.

[13] Hatton, T. J., and J. G. Williamson. "Are third world emigration forces abating?" World Development 39:1 (2011): 20-32.

\section{Online extras}

The full reference list for this article is available from:

http://wol.iza.org/articles/demographic-and-economic-determinants-of-migration

View the evidence map for this article:

http://wol.iza.org/articles/demographic-and-economic-determinants-of-migration/map 